\title{
Presentación Las motivaciones del voto en las elecciones republicanas
}

\author{
Daniel Camacho Monge \\ Director
}

Acerca de las causas o motivos que llevan a los electores a votar por unos u otros de los partidos en lisa, en una contienda electoral para elegir a las autoridades políticas en una República, existen abundantes explicaciones. Los estrategas de los partidos políticos son eficientes técnicos en ese campo. Algunos son tan certeros que han logrado altas cotizaciones en el mercado internacional de "expertos electorales".

En el fondo, sus estrategias son bastante esquemáticas, porque giran alrededor de dos extremos: el miedo y la esperanza. Muchos son los casos. En El Salvador, en las dos o tres elecciones anteriores al triunfo del FMLN de 2009, la propia Embajada de los Estados Unidos - hecho ampliamente comentado públicamente - difundió la especie de que ese país podría obstaculizar el envío de remesas desde Estados Unidos, si triunfaba la izquierda. Hechos similares se han dado con frecuencia en Nicaragua, suscitados por los mismos actores. En Costa Rica, durante la campaña del referéndum de 2007, una filtración oportuna de un memorándum cruzado ente autoridades de la cúpula del gobierno, dejó al descubierto y sin la menor sombra de duda, la utilización del miedo como motivación para elegir una opción del voto.

Ese aprisionamiento de los electores entre el miedo y la esperanza, es específico, según el sector social al cual va dirigido. En los Estados Unidos, a los sectores conservadores rurales se les atemorizó, por parte de la campaña para la reelección de George W. Bush, con la supuesta amenaza de agresiones árabes o islámicas, al propio territorio de los Estados Unidos.

Por el lado positivo, se despierta la esperanza con base en las promesas, generalmente no cumplidas, de programas de gobierno que elevarían la condición socioeconómica de la población en general o de sectores específicos. Es el caso, por ejemplo, de un "maravilloso" Tratado de Libre Comercio en el aludido referéndum, el cual generaría empleo, riqueza y bienestar. También se utilizó la esperanza frente al electorado femenino con la inédita candidatura de una mujer, en las elecciones costarricenses de 2008, lo cual suscitó la sensación de un posicionamiento mayor de las mujeres en la sociedad y una preferencia eventual por ellas en los programas de gobierno.

Estas estrategias electorales van dirigidas a la gran masa poco informada de electores. Parte de ella es conquistada también con pequeñas, medianas o grandes ventajas materiales, que van desde el obsequio de láminas de zinc para reparar el techo de las casas de las familias pobres, hasta cargos públicos desde los más humildes hasta los más elevados. Es el llamado clientelismo. 
La estrategia del miedo y la esperanza, en sí misma, no sería reprobable, si se fundamentara en hechos ciertos y promesas cumplidas. En otras palabras, si fueran reales las razones del miedo y los fundamentos de la esperanza; pero presenta interrogantes éticas, cuando son falaces.

El antídoto o contrapartida es la información. Un caso muy visible fue el vuelco espectacular de las intenciones de voto en el referéndum de 2007, sobre el Tratado de Libre Comercio. En el número 121 (III), 2008 de esta Revista de Ciencias Sociales, dedicado precisamente al análisis de ese referéndum, quedó clara la evolución de la intención de voto producida por la mayor información proporcionada en los debates. Cuando el gobierno aceptó el reto de la oposición para ir a una votación general sobre el tema del Tratado de Libre Comercio, una de las principales razones que tuvo para ello, fue la aplastante intención por el "Sí", la cual era cercana al $80 \%$. Sin embargo, la apertura de debates semanales en medios de comunicación masivos, sobre todo en televisión, organizados por el propio Tribunal Supremo de Elecciones, tuvo como efecto la disminución de la brecha entre ambas opciones. Conforme la gente obtenía mayor información de ambas partes, creció la oposición al Tratado, hasta el punto que el resultado final fue prácticamente un empate. La diferencia mínima concedió el triunfo a la tendencia del "Sí", porque alguna de las tesis debía ganar.

Este proceso puede mostrarse como base de una hipótesis, según la cual la información veraz, puede disminuir el grado de manipulación y aumentar el voto consciente.

Hay otras hipótesis acerca de las motivaciones del voto, pero no es esta la oportunidad para extenderse sobre ellas, porque los procesos electorales presentan múltiples ángulos de análisis y motivos de interés. Algunos se desarrollan en este número de la Revista de Ciencias Sociales, el cual es producto del "Foro de Análisis sobre el Proceso Electoral 2009-2010 en Costa Rica", celebrado en la Facultad de Ciencias Sociales de nuestra Universidad, los días $1^{\circ}, 2$ y 3 de noviembre de 2010.

Ese Foro se realizó porque, como dice la convocatoria:

... transcurridos ya ocho meses después de dicho proceso electoral, resulta oportuno y necesario realizar un análisis más detallado de la forma en que se desarrolló, así como de sus resultados, ya no al calor de la campaña misma, sino como una forma de leer la situación de uno de los componentes fundamentales de nuestra democracia representativa: las elecciones. Y por otro lado, hacerlo desde análisis académicos, profesionales y políticos con la partici-pación de distintas instancias de estudio e investigación, así como desde los propios actores participantes.

Por ello, el Centro de Investigación y Estudios Políticos (CIEP), el Programa de Posgrado Centroamericano en Ciencia Política (PCACP) y la Revista de Ciencias Sociales (RCS) de la Universidad de Costa Rica, convocaron a todas las personas interesadas, que estén realizando estudios, análisis o investigaciones sobre el proceso electoral 2010, a presentar ponencias, artículos académicos, resultados preliminares o finales de investigación para este foro, considerando los siguientes ejes temáticos: 
- Lecturas e interpretaciones globales del proceso y sobre la situación de la democracia representativa

- Análisis de los resultados y su comportamiento a nivel territorial

- Participación política y abstencionismo

- Experiencias de observación nacional e internacional de las elecciones

- Financiamiento a los partidos políticos

- Estudios de opinión: resultados y su papel en el proceso electoral

- Propaganda, información y comunicación en el proceso electoral

- Participación política de las mujeres en el proceso y los resultados electorales

- Balances del proceso y balances internos de los resultados alcanzados, desde la perspectiva de partidos participantes

- Administración, organización y resolución de conflictos del proceso electoral: el papel del Tribunal Supremo de Elecciones

- Papel de los medios de comunicación en el proceso electoral

- Nuevas tecnologías de información y comunicación en el proceso electoral

- Balances de las Reformas al Código Electoral (2009) y su impacto en el proceso electoral 2009-2010

- Actores no partidarios (grupos de presión, grupos de interés, organizaciones sociales, etc.) y su presencia en el proceso electoral.

El presente número de la Revista de Ciencias Sociales incluye algunas de las ponencias presentadas en esa oportunidad, las cuales dan cuenta de estudios y reflexiones sobre ángulos de análisis variados que suscitan los procesos electorales.

Entre ellos, existe interés de recuperar el comentario político analítico, sobre todo porque se ha puesto de moda un tipo de comentario, ejercido en algunos casos por personas que se autodefinen como analistas políticos y que no pasa de ser una superficial expresión de ocurrencias momentáneas, estimuladas por la fascinación de la cámara de televisión o el micrófono radiofónico.

El análisis político trata de traspasar la superficie y descender al entramado, en donde se desenvuelven los actores, se construyen los escenarios y se desatan las fuerzas. Esto exige la aplicación de un método para ordenar e interpretar los datos de la realidad y vislumbrar sus rumbos. Chinchilla, en el artículo que abre esta edición, trata de aplicar ese tipo de análisis al proceso eleccionario costarricense que culminó en el 2010.

Así lo hace también Sagot, centrada en la actuación política de las mujeres y la evolución de la legislación tendente a aumentar su participación, tanto en los procesos electorales en general, como en el derecho a ocupar puestos oficiales de representación política.

Jiménez, por su parte, trata de caracterizar el resultado del proceso electoral de 2010, como la consolidación del dominio del modelo neoclásico o neoliberal en la sociedad y la política costarricenses, además, señala los factores que según él, producen ese resultado.

El proceso electoral que culminó con las elecciones de 2010, objeto de análisis de este número de la Revista de Ciencias Sociales, tuvo como tema reiterado y persistente, el de la seguridad-inseguridad ciudadana. Por ser esta, la principal preocupación, según las 
encuestas de opinión, los partidos concentraron en él muchos de sus mensajes publicitarios. El Partido Movimiento Libertario puso la mayor parte de ese énfasis, hasta el punto de proponer la política de "mano dura" como solución del problema. García estudia la respuesta a esa proposición en los cantones con mayor incidencia de criminalidad.

Las elecciones de 2010, brindaron a Costa Rica la primera mujer electa Presidenta de la República. Ella obtuvo una mayoría considerable entre las mujeres y las personas adultas mayores. Flórez-Estrada contextualiza ese hecho en la nueva realidad demográfica, social y sexual del país y analiza si la Presidenta adelantará o no un nuevo pacto social y sexual en un escenario que, según Alfaro, no cambió significativamente el sistema de partidos de la época que se caracteriza como post-bipartidista.

Sáenz y Jiménez presentan el resultado de un estudio acerca de los "spots" publicitarios de cuatro partidos políticos y cómo se presenta en ellos la imagen de la mujer, la juventud, la política y lo que él llama la clase política.

Castro presenta un interesante estudio de lo que llama la contrapublicidad, ejercida por movimientos sociales de resistencia que tratan de contrarrestar la copiosa publicidad electoral de tipo consumista.

Acuña estudia la observación electoral como forma de participación ciudadana.

Por su lado, Blanco se introduce en el estudio de las fuerzas sociales que tienen influencia en la forma de constitución del Gabinete o Consejo de Gobierno y señala el papel de actores de tipo empresarial o de una precisa orientación ideológica.

Ramírez se ocupa de la vida política interna de los partidos políticos costarricenses y estudia si en ese ámbito los procesos son democráticos.

El número cierra con un artículo de Miranda, que no fue presentado en el Foro aludido anteriormente, pero que tiene un enorme interés porque se trata de la reconstrucción crítica del proyecto político educativo social demócrata del Partido Liberación Nacional, de finales de la década de los cincuenta. A nadie escapa la importancia histórica de ese proyecto educativo, el cual fue dominante desde esa época y lo sigue siendo hoy en sus aspectos básicos.

El análisis de Miranda es broche de oro para este número tan rico sobre la política costarricense.

Ciudad Universitaria Rodrigo Facio

Diciembre, 2010 